\title{
Meiosis in elephant grass (Pennisetum purpureum), pearl millet (Pennisetum glaucum) (Poaceae, Poales) and their interspecific hybrids
}

\author{
Vânia Helena Techio ${ }^{1}$, Lisete Chamma Davide ${ }^{2}$ and Antônio Vander Pereira ${ }^{3}$ \\ ${ }^{1}$ Universidade do Contestado, Concórdia, SC, Brazil. \\ ${ }^{2}$ Universidade Federal de Lavras, Departamento de Biologia, Lavras, MG, Brazil. \\ ${ }^{3}$ Embrapa Gado de Leite, Juiz de Fora, MG, Brazil.
}

\begin{abstract}
The cultivated and sexually compatible species Pennisetum purpureum (elephant grass, $2 n=4 x=28$ ) and Pennisetum glaucum (pearl millet, $2 \mathrm{n}=2 \mathrm{x}=14$ ) can undergo hybridization which favors the amplification of their genetic background and the introgression of favorable alleles into breeding programs. The main problem with interspecific hybrids of these species is infertility due to triploidy $(2 n=3 x=21)$. This study describes meiosis in elephant grass $x$ pearl millet hybrids and their progenitors. Panicles were prepared according to the conventional protocol for meiotic studies and Alexander's stain was used for assessing pollen viability. Pearl millet accessions presented regular meiosis with seven bivalents and high pollen viability. For elephant grass, 14 bivalents in diakinesis and metaphase I were observed. The BAG 63 elephant grass accession, derived from tissue culture, presented a high frequency of meiotic abnormalities. The three hybrid accessions presented a high frequency of abnormalities characterized by irregular chromosomal segregation which resulted in the formation of sterile pollen.
\end{abstract}

Key words: meiosis, Pennisetum, elephant grass, interspecific hybrids, pearl millet, pollen.

Received: November 5, 2004; Accepted: November 11, 2005.

\section{Introduction}

The first reports of cytogenetic studies in Pennisetum were made by Rao (1929) and Avdulov (1931), followed by other authors (Burton, 1942; Veyret, 1957, Burton and Powell 1968; Jauhar, 1968 and 1981; Harlan and De Wet, 1971). They established the chromosome basic number (x) as five, seven, eight or nine. Also, the species were divided into three gene pools and different ploidy levels varying from diploid to octaploid.

The most economically important Pennisetum species are the cereal and forage crop pearl millet $(P$. glaucum) and the forage crop elephant grass ( $P$. purpureum). Pearl millet is an annual allogamic species with a chromosome complement of $2 \mathrm{n}=2 \mathrm{x}=14$ and an AA genome integrating the primary gene pool together with Pennisetum violaceum and Pennisetum mollissimum. Elephant grass is a perennial allogamic species with a chromosome complement of $2 \mathrm{n}=4 \mathrm{x}=28$ and an $\mathrm{A}^{\prime} \mathrm{A}^{\prime} \mathrm{BB}$ genome belonging to the secondary gene pool. In the third group are the other taxa (Harlan and De Wet, 1971; Martel et al., 1996).

Send correspondence to Vânia Helena Techio. Universidade do Contestado, Campus Universitário de Concórdia, Caixa Postal 211, 89700.000 Concórdia, SC, Brazil. E-mail: vht@uncnet.br.
Pearl millet and elephant grass are sexually compatible even though they integrate different gene pools and present differentiated ploidy levels, and this allows the introgression of desirable pearl millet alleles, such as drought resistance and larger seed size, to elephant grass genotypes of agricultural importance.

However, the greatest problem related to the utilization of elephant grass and pearl millet hybrids is infertility caused by triploidy $(2 \mathrm{n}=3 \mathrm{x}=21$, AA'B genome). Meiotic studies accomplished by Pantulu (1967), Sree Rangasamy (1972) and Jauhar (1968 and 1981) showed that the usual result of diakinesis is the formation of seven bivalent chromosome of A and A' genomes of pearl millet and elephant grass, respectively, and seven univalents of B genome derived from the elephant grass as well. In general, the univalents display irregular segregation, causing the formation of aneuploid gametes.

However, the descriptions in the literature do not establish correlations between the meiosis of elephant grass and pearl millet genotypes and their respective hybrids in relation to abnormalities caused by irregular segregation, i.e. when considering analysis at the level of complete families of progenitors and their descendants. The analysis of the chromosomal behavior of hybrids presupposes an understanding of the cytogenetic behavior of their progenitors 
because different genetic combinations can produce different degrees of irregularities in the descendants. Furthermore, except for pearl millet, for which a number of cytogenetic reviews are available (e.g. Burton and Powell, 1968; Jauhar, 1981; Pantulu and Rao, 1982; Minocha, 1991; Jauhar and Hanna, 1998), there are few references concerning meiosis in $P$. purpureum and $P$. purpureum $x P$. glaucum hybrids and, in general, any data which is published is presented separately (Pantulu and Venkateswarlu, 1968; Sree Rangasamy, 1972; Sujatha et al., 1989).

The aim of this study was to analyze meiosis in elephant grass and pearl millet accessions and their respective hybrids, comparing the cytogenetic aspects of the progenitors and their relationship with the degree of meiotic irregularities in the descendants.

\section{Material and Methods}

The biological material used in this study was collected between April to July 1999 to 2002 from plants in the Forage Germplasm Active Bank of Embrapa Gado de Leite, in the town of Coronel Pacheco in the Brazilian, Minas Gerais State. The pearl millet and elephant grass accessions (Table 1) were selected based on complementary genetic characteristics of forage importance.

Panicles were collected and then prepared using the conventional protocol for meiotic studies, i.e. smearing and staining with $0.5 \%$ propionic carmine (Sharma and Sharma, 1994). For each genotype we assessed 1300 cells, normal cells and meiotic irregularities being quantified and the frequency of abnormalities for the total analyzed cells obtained. In the hybrids, the univalents were considered as irregularities when they exceeded the expected segregation pattern of seven bivalents and seven univalents. To determine meiotic index we evaluated 150 tetrads of each accession, and those presenting a meiotic index in excess of $90 \%$ were considered stable plants (Love, 1951).

Table 1 - The Pennisetum progenitors and hybrids evaluated.

\begin{tabular}{l} 
Pennisetum accessions (Common name or cross) \\
\hline P. purpureum (elephant grass) \\
BAG 63 (Cuba 169) \\
BAG 75 (IJ 7136) \\
BAG 91 (Pasto Panamá) \\
\hline P. glaucum (pearl millet) \\
M 24 (ICMB 90111) \\
M 36 (AFPOP 88) \\
M 38 (AFPOP 90) \\
\hline Interspecific hybrids \\
CNPGL F94-44-03 (BAG 63 x M 36) \\
CNPGL F94-60-01 (BAG 75 x M 24) \\
CNPGL F94-49-06 (BAG 91 x M 38)
\end{tabular}

Pollen viability was estimated by the Alexander staining technique (Alexander, 1980), pollen grains stained purple being considered viable while those stained green were considered non-viable. For pollen viability analysis 10 slides and 100 pollen grains per slide were evaluated for each accession, pollen always being collected between 8:30 and $10 \mathrm{a} . \mathrm{m}$. when the anthers started to become dehiscent and when it is believed that viability was maximum in the species studied.

\section{Results and Discussion}

\section{Meiosis in pearl millet accessions M24, M36 and M38}

Each of the pearl millet accessions showed seven bivalents during diakinesis and metaphases I (Figure 1A, B), supporting the observations made by other authors (Burton and Powell, 1968; Jauhar, 1981; Jauhar and Hanna, 1998).

There was a very low $(0.4 \%)$ chromosomal abnormality rate, with the early ascension of chromosomes, observed in the three accessions, being the most frequent. The percentage of normal tetrads, expressed as the average meiotic index, was $99.7 \%$ and pollen viability was $100 \%$.

Fast chiasma terminalization has been observed during diakinesis as a characteristic of these accessions (Jauhar, 1981; Jauhar and Hanna, 1998), which means that during diakinesis and metaphase I the bivalent chromosomes often appears dissociated as 14 univalents (Figure 1C). Most of the bivalents observed during diakinesis presented a ring form with chiasma terminalization with two of them frequently appearing in a stick or open form (Figure 1A). The precocious migration in metaphase I could be attributed to these two bivalents.

In the M36 and M38 accessions the small bivalent chromosome associated with the nucleolus during diakinesis (Figure 1A), as did the two nucleolar bivalents in the M24 accession (Figure 1B). Barbosa et al. (2003) showed that mitotic metaphases of accessions M36 and M38 had two chromosomes with satellites but for accession M24 only one chromosome presented a satellite, indicating that there was variation among pearl millet varieties in respect to the occurrence of satellites and supporting previous work by other authors (Pantulu, 1968; Burton and Powell, 1968; Jauhar, 1981). Such variations may be attributable to chromosomal rearrangements or to mistakes in the interpretation of chromosomal morphology during mitotic analysis.

The M24 and M38 accessions showed quadrivalent configurations during diakinesis and metaphase I (Figure 1A), with Jauhar (1981) describing such an event as being due to secondary association of two bivalents. Other explanations are the occurrence of translocation, already reported in pearl millet (Pantulu, 1968; Powell and Burton, 1969; Pantulu and Rao, 1982), or chromosomal duplication during the evolution of these species, based on which 


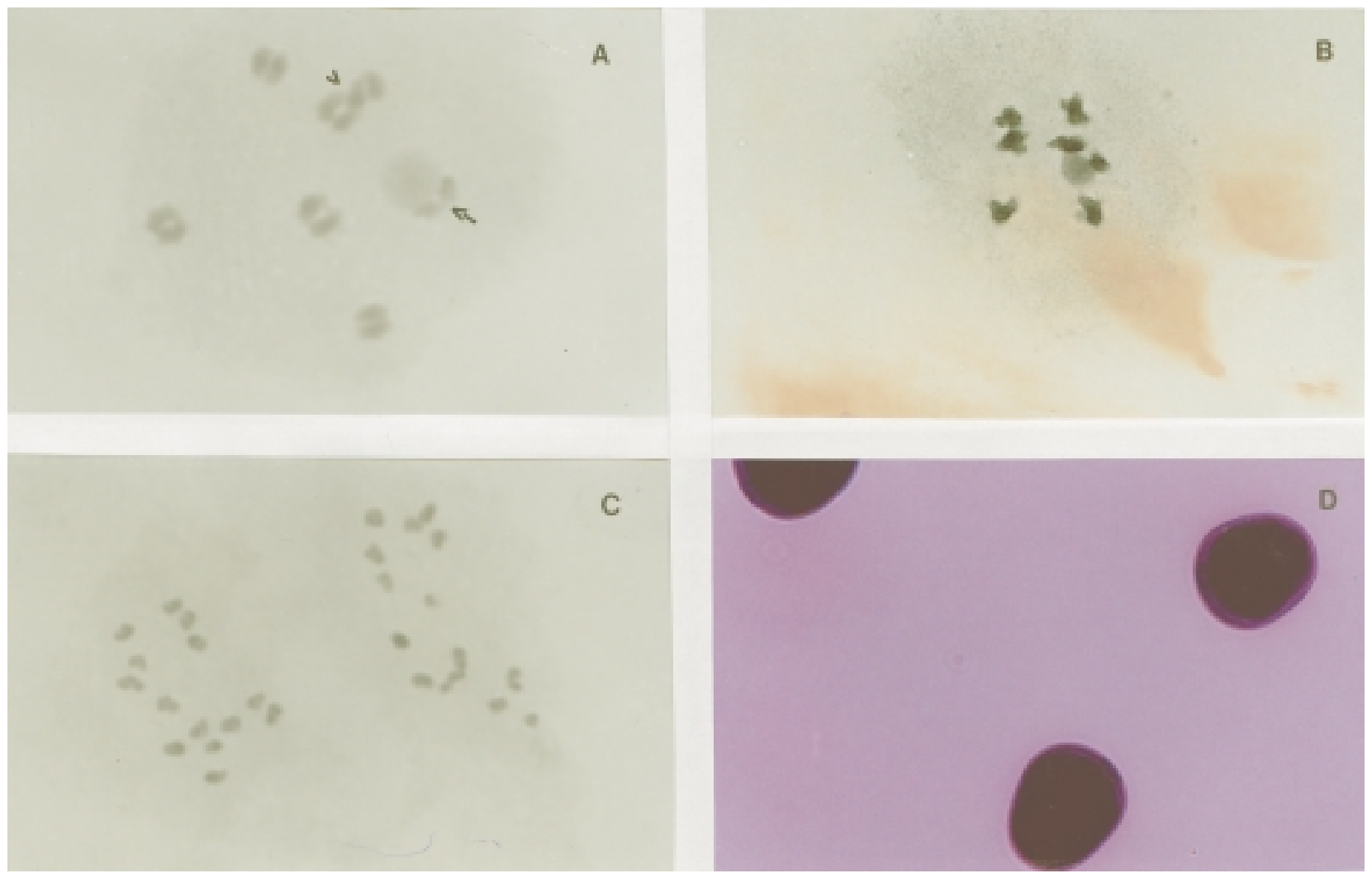

Figure 1 - Meiotic cells and pollen grains of the pearl millet accessions. $\mathrm{A}=$ diakinesis with 7 bivalents and one nucleolar bivalent (arrow $=$ open bivalent; headed arrow $=$ quadrivalent configuration); $\mathrm{B}=$ diakinesis with two nucleolar bivalents; $\mathrm{C}=$ metaphase $\mathrm{I}$ with 14 univalents; $\mathrm{D}=$ viable pollen grains (Alexander's stain).

Jauhar $(1968,1981)$ suggested that the chromosomal complement of pearl millet arose from an original, or primary, basic chromosome number of five.

In relation to pollen viability, staining tests showed that the pearl millet accessions presented $100 \%$ fertility (Figure 1D). In the accessions analyzed the maximum pollen viability observed by pollen staining was associated with meiotic regularity and the collection schedule (standardized between 8:30 and 10 a.m.), at which time the anthers start to become dehiscent and it is believed that pollen viability reaches a maximum.

\section{Meiosis in elephant grass accessions BAG 63, BAG 75 and BAG 91}

The frequent formation of 14 bivalents during diakinesis and metaphase I of all the accessions (Figure 2A) confirms that although elephant grass is allotetraploid it behaves as a typical diploid in terms of chromosomal segregation (Jauhar, 1968 and 1981; Sujatha et al., 1989). This suggests that elephant grass may have homeologous pairing suppresser genes as is the case in wheat (Riley and Chapman, 1958; Sears, 1976).

We found both univalents and trivalents in BAG 63 and in BAG 91 (Figure 2B), while BAG 63 presented the largest frequency of abnormalities of the all the elephant grass accessions analyzed (Table 2, Figure 2C). The BAG 63 accession was obtained using apical meristem callus culture by Martinez et al. (1986), who referred to it as Cuba $\mathrm{T} 169$, and is considered to be a mutant which is different in width, height, angle of leaf insertion, stem forms and seasonal dimorphism as compared to the explant donor plant (Martinez et al., 1990). The artificial culture media, growth regulators, genotype and age of the culture have all been suggested as the principal sources of the cytogenetic alterations (Bayliss, 1980; Peschke and Phillips, 1992; Sybenga, 1992), which vary from non-disjunction to chromosomal structural aberrations (Sybenga, 1992).

Analysis of BAG 63 meiosis showed that the behavior of univalents and trivalents resulted in about $8 \%$ of cells with irregular segregation and micronucleus formation in meiosis I (Table 2). Some of the chromosomes that arrived early or late at the poles might have been included in the nucleus where they formed meiotic normal products, since tetrads with micronucleus were approximately $1 \%$ (Table 2).

The presence of multivalents suggests that translocations have occurred in BAG 63 and BAG 91 (Table 2, Figure 2B). Although cross and ring configurations were not observed in pachytene and diakinesis, the multivalent configuration seen by us in diakinesis may have been due to 


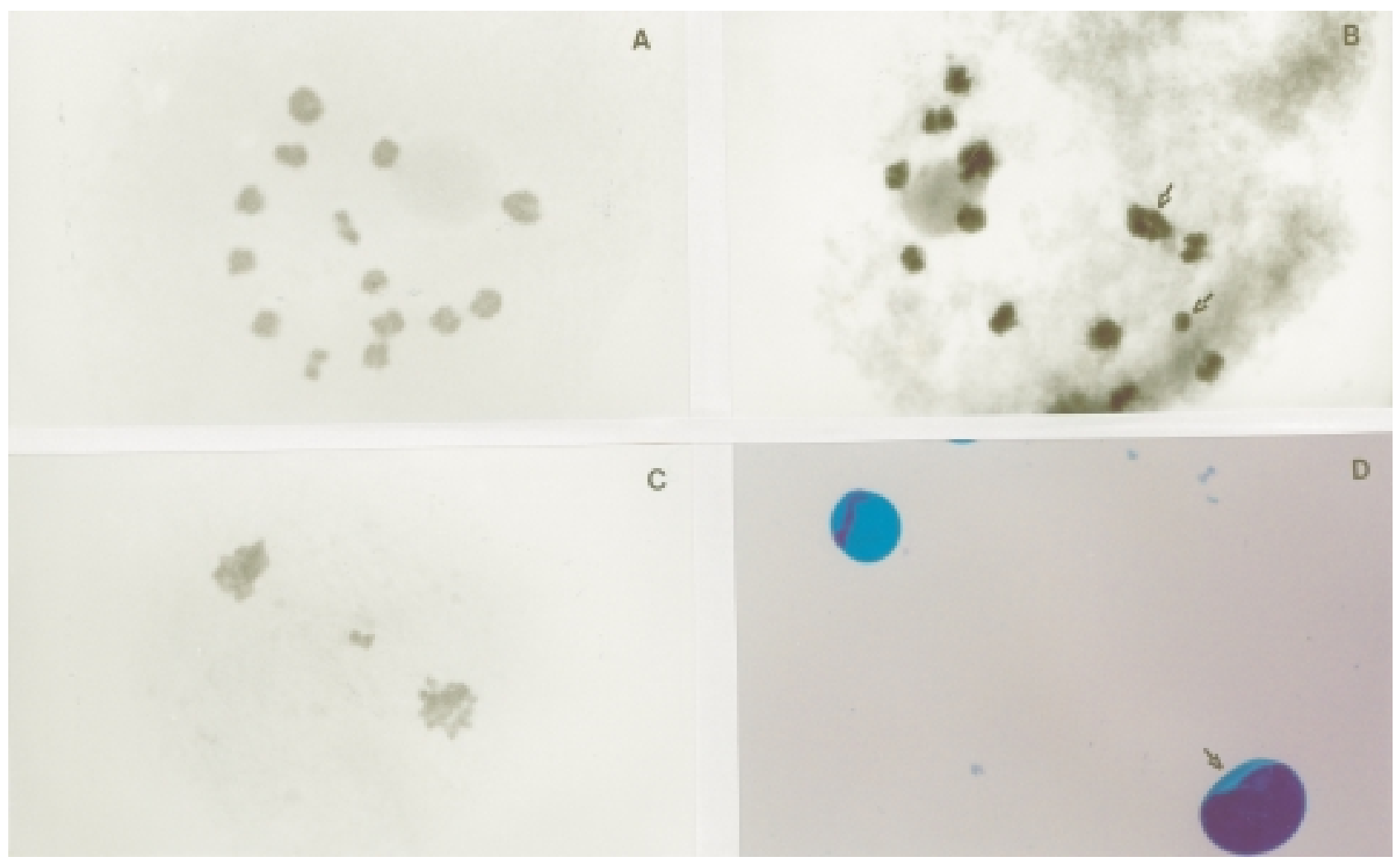

Figure 2 - Meiotic cells and pollen grains of the elephant grass accessions. A = diakinesis with 14 bivalents with two nucleolar bivalents; $\mathrm{B}=$ diakinesis with three nucleolar bivalents and trivalent and univalent configurations (arrows); C = telophase I with late chromosomes; $\mathrm{D}=$ viable (arrow) and non-viable pollen grains (Alexander's stain).

ring-breakage caused by fast chiasma terminalization, a known characteristic of elephant grass chromosomes (Jauhar, 1981).

Other abnormalities observed in BAG 63 were sticky chromosomes, asynchronous nuclei, microcells and anucleate cells (Table 2). The microcells and anucleate cells are characteristic of cytomixis, considered an additional mechanism of aneuploidy and polyploidy, reflecting in the pollen fertility (Pagliarini, 2000).

The various cytogenetic anomalies observed in BAG 63 were reflected in the low pollen viability of this accession (71.7\%, Table 2$)$ as verified by staining. Love (1951) recommended measuring meiotic instability using the meiotic index and applying this to the selection of genotypes for crossings, based on which BAG 63 presents a meiotic index below which the plants would not be recommended for use as breeding material.

The BAG 75 and BAG 91 functional pollen frequency as obtained by staining was about $99 \%$ (Table 2, Figure 2D), similar to the $95 \%$ reported by Sree Rangasamy (1972) but considerably higher than the approximately $62 \%$ recorded by Sethi et al. (1970) and the $78 \%$ reported by Sujatha et al. (1989)

In the three genotypes analyzed, two bivalents were associated with the nucleolus (Figure 2A), although three nucleolar bivalents were observed during diakinesis in
BAG 63 (Figure 2B). Barbosa et al. (2003), in the mitotic analysis of these accessions, observed that the largest BAG 75 and BAG 91 chromosome was associated with a satellite, while for BAG 63 satellites were observed in the 1st and 4th chromosomes of the complement. The observation of three nucleolar bivalents in elephant grass (Figure 2B) has not previously been reported by other authors. Jauhar (1981) observed that additional nucleolar material can occasionally appear in meiotic Pennisetum cells, and this was also by us in BAG 91 and BAG 63. Concerning intraspecific variation, it should be remembered that elephant grass contains chromosomes from both $\mathrm{A}^{\prime}$ and $\mathrm{B}$ genomes, the $\mathrm{A}^{\prime}$ genome originating from a progenitor which is also common to pearl millet and the B genome from an unknown progenitor (Jauhar, 1981). Elephant grass can also manifest nucleolar dominance, a common phenomenon in some species (Flavell and O'Dell, 1979) and hybrids belonging to several genera (Lange, 1969; Pickersgill, 1991; Vieira, 1992; Hemlebem, 2002).

\section{Meiosis in elephant grass and pearl millet interspecific hybrid accessions F94-44-03, F94-49-06 and F94-60-01}

Several abnormalities occurring between the initial phases and the formation of the meiotic products characterized the meiotic cycle of these hybrids (Figures 3 and 4). 
Table 2 - Observed frequency (\%) of cells with meiotic abnormalities along with the meiotic index and frequency of viable pollen grains (\%) in elephant grass accessions and elephant grass and pearl millet interspecific hybrids.

\begin{tabular}{|c|c|c|c|c|c|c|}
\hline Cell-cycle phases and abnormality & $\begin{array}{c}\text { F94-44-03 } \\
\text { ( BAG 63 x M36) }\end{array}$ & $\begin{array}{c}\text { F94-60-01 } \\
\text { (BAG 75 x M24) }\end{array}$ & $\begin{array}{c}\text { F94-49-06 } \\
\text { (BAG 91 x M38) }\end{array}$ & BAG 63 & BAG 75 & BAG 91 \\
\hline \multicolumn{7}{|l|}{ Meiosis I } \\
\hline Univalents & 5.6 & 6.3 & 5.6 & 0.3 & 0.0 & 0.2 \\
\hline Multivalents & 0.6 & 1.2 & 0.9 & 0.7 & 0.0 & 0.2 \\
\hline Early migration chromosome ${ }^{1}$ & 4.1 & 2.7 & 6.7 & 2.2 & 1.2 & 1.2 \\
\hline Irregular segregation $^{2}$ & 8.5 & 4.0 & 8.8 & 2.0 & 0.3 & 0.0 \\
\hline Micronucleus & 0.7 & 1.4 & 1.2 & 6.4 & 0.0 & 0.0 \\
\hline Bridges & 3.5 & 1.5 & 3.8 & 0.5 & 0.2 & 0.0 \\
\hline Sticky chromosome & 1.7 & 1.8 & 2.0 & 2.2 & 0.2 & 0.0 \\
\hline Asynchronous nucleus & 0,8 & 0.6 & 0.1 & 0.3 & 0.1 & 0.0 \\
\hline Unequal cells & 0.0 & 0.1 & 0.0 & 0.4 & 0.0 & 0.0 \\
\hline Cytomixy & 0.5 & 0.0 & 0.0 & 0.0 & 0.0 & 0.0 \\
\hline Abnormal spindle & 0.1 & 0.0 & 0.0 & 0.0 & 0.0 & 0.0 \\
\hline Binucleated & 0.0 & 1.3 & 0.8 & 0.0 & 0.0 & 0.0 \\
\hline Enucleated cells & 0.0 & 0.0 & 0.0 & 0.7 & 0.0 & 0.0 \\
\hline \multicolumn{7}{|l|}{ Meiosis II } \\
\hline Early migration & 2.1 & 1.6 & 0.0 & 0.0 & 0.0 & 0.0 \\
\hline Irregular segregation ${ }^{2}$ & 4.8 & 0.3 & 3.0 & 1.2 & 0.0 & 0.3 \\
\hline Micronucleus & 2.4 & 4.0 & 1.0 & 0.6 & 0.0 & 0.0 \\
\hline Bridges $^{4}$ & 0.7 & 1.6 & 3.4 & 0.0 & 0.0 & 0.2 \\
\hline Sticky chromosome & 0.0 & 0.0 & 0.5 & 0.3 & 0.0 & 0.0 \\
\hline Abnormal spindle & 0,0 & 0.4 & 0.0 & 0.0 & 0.0 & 0.0 \\
\hline Asynchronous nucleus & 0.6 & 0.3 & 0.0 & 0.0 & 0.0 & 0.0 \\
\hline Unequal nucleus & 0.6 & 1.5 & 0.0 & 0.5 & 0.0 & 0.0 \\
\hline Additional microcell & 1.4 & 0.0 & 0.0 & 0.0 & 0.0 & 0.0 \\
\hline \multicolumn{7}{|l|}{ Meiotic products } \\
\hline Triads & 0.7 & 1.2 & 0.1 & 0.0 & 0.0 & 0.0 \\
\hline Polyads & 0.4 & 0.2 & 0.2 & 0.0 & 0.2 & 0.6 \\
\hline Tetrads with micronucleus & 8.0 & 9.0 & 8.2 & 1.1 & 0.0 & 0.0 \\
\hline Tetrads with bridges & 0.1 & 0.0 & 0.0 & 0.0 & 0.0 & 0.0 \\
\hline Tetrads with nucleated microspore & 0.2 & 0.0 & 0.1 & 0.0 & 0.0 & 0.0 \\
\hline Microspore with micronucleus & 4.3 & 4.6 & 4.1 & 1.5 & 0.0 & 0.2 \\
\hline Total & 52.4 & 45.6 & 50.5 & 20.9 & 2.2 & 2.7 \\
\hline $\mathrm{MeI}^{5}$ & 41.1 & 35.8 & 28.8 & 90.9 & 98.6 & 96.4 \\
\hline $\mathrm{SPV}^{6}$ & 0.0 & 0.0 & 0.0 & 71.7 & 99.9 & 99.8 \\
\hline
\end{tabular}

${ }^{1}$ in metaphases; ${ }^{2}$ in anaphase and telophase; ${ }^{3}$ in anaphase and telophase; ${ }^{4}$ in prophases, anaphase and telophase; ${ }^{5} \mathrm{MeI}=\mathrm{Meiotic}$ index; ${ }^{6} \mathrm{SPV}=\mathrm{Pollen}$.

The F94-44-03 hybrid showed the highest frequency of meiotic disturbances $(\approx 52 \%)$ and had BAG 63 as a progenitor, BAG 63 being the elephant grass accession with the highest number of meiotic abnormalities (Table 2). However, the F94-49-06 hybrid also showed a high rate of irregularities $(\approx 50 \%)$ while the F94-60-01 hybrid presented about $45 \%$ of irregularities (Table 2). It is interesting to observe that the pairing relationships estimate by Techio et al. (2005), with the same accessions, showed that M24 (pearl millet) and BAG 75 (elephantgrass) accessions, progenitors of hybrids F94-60-01, present the major genetic proximity among their chromosomal complement.

Triploidy is known to result in the formation of univalents which exhibit irregular segregation leading to aneuploid gametes which cause abnormalities and infertility in elephant grass and pearl millet hybrids (Jauhar, 1968 and 1981; Sethi et al., 1970; Sree Rangasamy, 1972).

We found that the univalent and multivalent frequency varied among the accessions studied (Table 2, Fig- 
ure 3A) but was especially high in the F94-60-01 hybrid (Table 2), evidently influenced by the genotypes of the parents. Such differentiated behavior also occurred in the F94-49-06 hybrid as indicated by the frequency of chromosomes with early ascension (6.7\%) and irregular segregation during meiosis I ( $8.8 \%$ ), figures which were higher in this hybrid as compared with the other accessions (Table 2, Figure $3 \mathrm{~B}, \mathrm{C}, \mathrm{E}$ ). Figure $3 \mathrm{C}$ shows the segregation and migration of only seven chromosomes, possibly representing only one of the genomes, to one of the cell poles, suggesting the formation of two types of pollen, large fertile pollen grains containing 14 chromosomes and small sterile pollen grains with seven chromosomes.

Measurements accomplished by Assis et al. (2002) in these accessions showed that the average diameter of the pollen grain varies from 39.2 to $44.1 \mathrm{~mm}$. However, some pollen grains were observed with up to 81.8 and $85.7 \mathrm{~mm}$ and also with 8.3 and $13.2 \mathrm{~mm}$ (Figure 3D). During the fertility evaluations the presence of fertile pollen was not verified (Table 2, Figure 3D).

Observation of the univalent, bivalent and trivalent configuration at diakinesis and metaphases I showed that the pearl millet A genome chromosomes were larger than the chromosomes from the A' and B elephant grass genomes (Figure 3A). All the bivalents were formed from allosindetic pairing involving chromosomes from both the A and A' genomes, similar findings having been reported in Pennisetum by Jauhar (1968). We found that many of the bivalents were heteromorphic (Figure 3A) and confirms that there were different segments among these chromosomes. Such heteromorphism supports the homeology of A and A' genomes proposed by Jauhar $(1968,1981)$ but not the homology suggested by other authors (Krishnaswamy and Raman, 1956; Raman, 1964; Pantulu, 1967). The fact that up to seven bivalents were observed does not confirm the autosindetic pairing suggested by Jauhar $(1968,1981)$ but, nevertheless, the formation of trivalents in the hybrids (Figure $3 \mathrm{~A}$ ) and the quadrivalent configurations observed in the pearl millet progenitor (Figure 1A) suggest the presence of intragenomic homology.

In relation to the nucleolus organizer regions (NORs), the three hybrid accessions exhibited two bivalents associated with the nucleolus. Barbosa et al. (2003) reported satellites in two F94-44-02 mitotic chromosomes and in one F94-49-06 and one F94-60-01 chromosome.

All three hybrids showed loss of genetic material during microsporogenesis and in meiosis I irregular segregation occurred at an average frequency of $7 \%$ (Table 2 , Figure 3B, C). In several anaphase I and telophase I, metaphasic chromosomes were seen to be aligned at the equatorial plate (Figure 3E), with one to three micronuclei being observed in telophase I (Figure 3F) showing that some late chromosomes were not included in the nucleus. With accession F94-44-03 for example additional microcells were visible during prophase and metaphase of meiosis II (Fig- ure $3 \mathrm{G}$ ) and chromosomal segregation was evident (Figure $3 \mathrm{H}$ ). Micronuclei were also observed in the tetrads (Figure $4 \mathrm{~A})$ and microspores and the micronuclei probably developed microcytes that resulted in small and sterile pollen grains (Figure 3D).

Chromosomal elimination by micronucleus formation is common in interspecific and intergeneric hybrids and has already been reported in several genera (Davies, 1974; Gupta, 1969; Pijnacker et al., 1989), including Pennisetum (Gildenhuys and Brix, 1964; Raman and Krishnaswamy cited by Jauhar, 1981; Abreu, 2002).

In meiosis I and II, all three hybrids showed single and multiple bridges, both with and without the presence of fragments (Table 2, Figure 4B, C), which were of variable size and were also observed during telophase when they usually occurred at the equatorial plate (Figure 4D). Sybenga (1992) has pointed out that bridges accompanied by chromosome fragments usually result from paracentric inversions while the absence of fragments may be due to misdivision events, while sticky chromosomes and late chiasma terminalization are also known to be bridge-generating mechanisms (Baptista-Giacomelli et al., 2000). In the hybrids analyzed by us the frequency of sticky chromosomes and bridges was highest in the F94-49-06 hybrid, being $2.5 \%$ for meiosis I and about $10 \%$ for meiosis II (Table 2). Many bridges were visible in telophase I and other phases of meiosis II (Figure 4B, C), the fusion of two telophase II nuclei, probably due to chromatin adherence, being shown in Figure 4E.

Although a literature search showed no previous report of cytomixy in Pennisetum we observed both cytomixy and tripolar spindles (Figure 4F) in the F94-44-03 hybrid (Table 2). Cytomixy certainly contributes to reducing the viability of the hybrid plants by causing other abnormalities such as myxoploidy and cell fusion. We observed the formation of triads in the second division of F94-44-03 hybrid cells (Figure 4G) because of tripolar spindle formation (Figure 4F).

All the cytogenetic irregularities in the hybrids mentioned in this paper contributed to the formation of abnormal microspores, which varied from binucleate to multinucleate and sterile and different sized pollen grains were also observed (Figure 3D).

The divergence in the frequency of normal tetrads (meiotic index), or even between the rate of irregularities and the percentage of sterile pollen grains (Table 2) can be explained in two ways, the more probable explanation being that not all the tetrads identified as normal present the four microspores with balanced chromosome number but it is also possible that post-meiotic alterations can affect pollen fertility.

The comparative analysis of meiosis within complete families of progenitors and descendants showed that not only meiotic abnormalities but also, and principally, inter- 

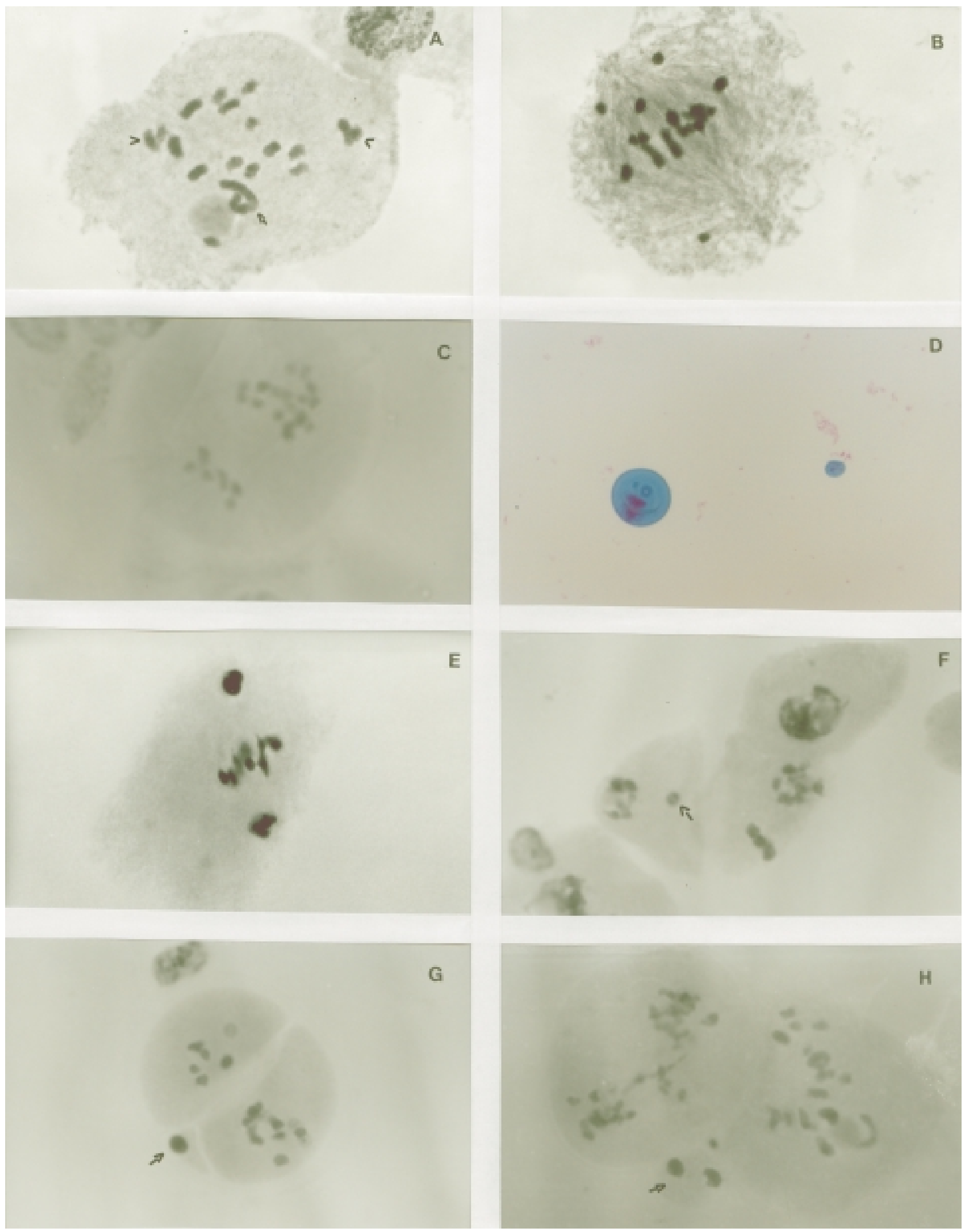

Figure 3 - Meiotic cells and pollen grains of the elephant grass and pearl millet hybrid accessions. A = diakinesis with multivalent and univalent (arrow) and heteromorphic bivalent (headed arrow) configurations; B = metaphase I with early migration of chromosome; $\mathrm{C}=$ anaphase I with seven chromosomes at the cell pole; $\mathrm{D}=$ non-viable and different-sized pollen grains (Alexander's stain); $\mathrm{E}=$ telophase $\mathrm{I}$ with metaphasic chromosomes; $\mathrm{F}=$ telophase I with micronucleus (arrow) and late chromosomes; $\mathrm{G}=$ metaphase II with additional microcell (arrow); $\mathrm{H}=$ telophase microcell (arrow). 

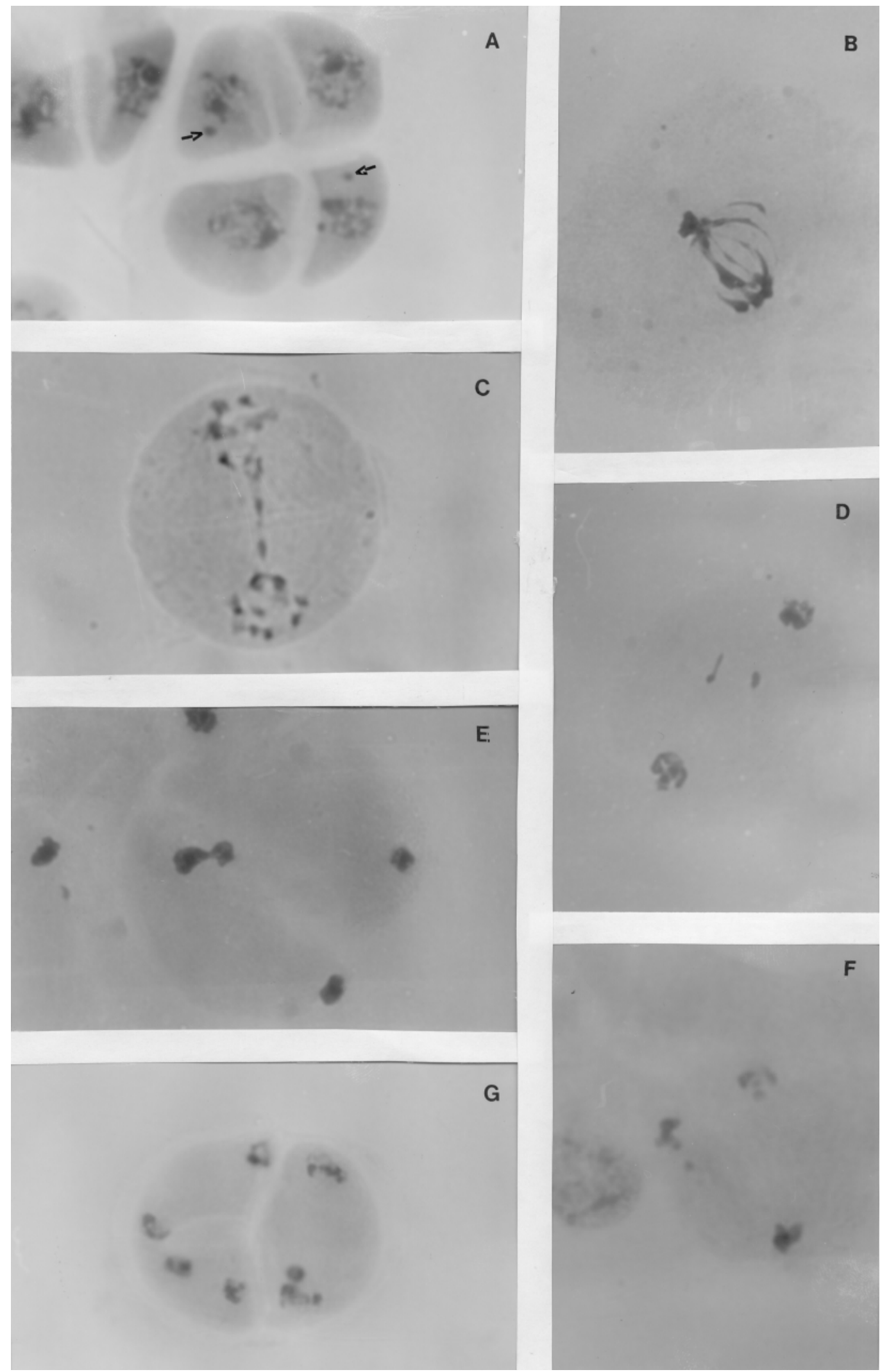

Figure 4 - Meiotic cells of the elephant grass and pearl millet hybrids accessions $\mathrm{A}=$ tetrad with micronucleus (arrows); $\mathrm{B}=$ telophase I with multiples bridges; $\mathrm{C}=$ prophase II with bridge; $\mathrm{D}=$ telophase I with fragments and late chromosomes; $\mathrm{E}=$ telophase II with nuclear fusion; $\mathrm{F}=$ tripolar spindle; $\mathrm{G}=$ triad with binucleated microspore. 
actions between A, A' and $\mathrm{B}$ genomes are responsible for the cytogenetic behavior of the hybrids.

\section{Acknowledgments}

The authors thank the Brazilian agencies FAPEMIG and $\mathrm{CNPq}$ for the financial support for this research.

\section{References}

Abreu JC (2002) Mixoploidia em híbridos de capim-elefante $x$ milheto tratados com agentes antimitóticos. Tese de Doutoramento, Universidade Federal de Lavras, Lavras.

Alexander MP (1980) A versatile stain for pollen from fungi, yeast and bacteria. Stain Technol 55:13-18.

Assis JC, Pedrozo CA, Barbosa S, Techio VH, Davide LC and Pereira AV (2002) Determinação do nível de ploidia em Pennisetum spp.: Área nuclear, tamanho da placa metafásica e diâmetro do pólen. Programa e Resumos: $48^{\circ}$ Congresso Nacional de Genética, SBG, Águas de Lindóia, Brasil.

Avdulov NP (1931) Karyosystematicshe Untersuchung der Familie Graamineen. Bulletin Applied Botany of Genetics and Plant Breeding 4:1-428.

Baptista-Giacomelli FR, Pagliarini MS and Almeida JL (2000) Multiple anaphase bridges on meiosis in Brazilian oats (Avena sativa L.). Nucleus 43:58-63.

Barbosa S, Davide LC and Pereira AV (2003) Cytogenetic of Pennisetum purpureum Schumach. x Pennisetum glaucum L. hybrids and their parents. Ciência e Agrotecnologia 27:26-35.

Bayliss MW (1980) Chromosomal variation in plant tissues in culture. Int Rev Cytol 11:113-144.

Burton GW (1942) A cytological study of some species in the Tribe Paniceae. Am J Bot 29:355-361.

Burton GW and Powell JB (1968) Pearl millet breeding and cytogenetics. Adv Agron 20:49-89.

Davies DR (1974) Chromosome elimination in inter-specific hybrids. Heredity 32:267-270.

Flavell RB and O'Dell M (1979) The genetic control of nucleolus formation in wheat. Chromosoma 71:135-152.

Gildenhuys P and Brix K (1964) Genetically controlled variability of chromosome number in Pennisetum. Heredity 19:533542 .

Gupta SB (1969) Duration of mitotic cycle and regulation of DNA replication in Nicotiana plumbaginifolia and a hybrid derivative of $N$. tabacum showing chromosome instability. Can J Genet Cytol 11:133-142.

Harlan JR and De Wet JMJ (1971) Toward a rational classification of cultivated plants. Taxon 20:509-517.

Hemlembem V (2002) Genome organization and molecular evolution in higher plants. Universitat Tubingen, http://www. uni-tuebingen.de/ZMBP/research/gghemleben.html.

Jauhar PP (1968) Inter- and intra-genomal chromosome pairing in an inter-specific hybrid and its bearing on the basic chromosome number in Pennisetum. Genetica 39:360-370.

Jauhar PP (1981) Cytogenetics of pearl millet. Adv Agron 34:407-479.

Jauhar PP and Hanna WW (1998) Cytogenetics and genetics of pearl millet. Adv Agron 64:1-26.
Krishnaswamy N and Raman VS (1956) Studies on the interspecific hybrid of Pennisetum typhoides $\mathrm{x} P$. purpureum IV. Cytogenetics of the allotetrapoids. Genetica 28:345-360.

Lange W (1969) Cytogenetics en embryologisch onderzoek an kruisingen tussen Hordeum vulgare en H. bulbosum. Wageningen http://www.agralin.nl/wda/abstracts/ab439.html.

Love RM (1951) Varietal differences in meiotic chromosome behavior of Brazilian wheats. Agron J 43:2-6.

Martel E, Richroch A and Sarr A (1996) Assessment of genome organization among diploid species $(2 \mathrm{n}=2 \mathrm{x}=14)$ belonging to primary and tertiary gene pools of pearl millet using fluorescent in situ hybridization with rDNA probes. Genome 39:680-687.

Martinez RO, Herrera R, Monzote M and Cruz R (1986) El Cultivo de Tejidos y la Obtención y Selección de Mutantes Los Pastos en Cuba Producción. Edica Instituto de Ciencia Animal, La Habana.

Martinez RO, Herrera R, Monzote M and Cruz R (1990) Obtencion de mutantes utilizando el cultivo de tejidos y otras tecnicas. In: Herrera RS (ed) King Grass Plantacion Establecimento y Manejo en Cuba. Edica Instituto de Ciencia Animal, La Habana, pp 11-42.

Minocha JL (1991) Pearl millet cytogenetics. In: Gupta PK and Tsuchiya T (eds) Chromosome Engineering in Plants: Genetics, Breeding, Evolution Part A. Elsevier, New York, pp 599-611.

Pagliarini MS (2000) Meiotic behavior of economically important plant species: The relantionship between fertility and male sterility. Genet Mol Biol 23:997-1002.

Pantulu JV (1967) Pachytene pairing and meiosis in the F1 hybrid of Pennisetum typhoides and $P$. purpureum. Cytologia 32:532-541.

Pantulu JV (1968) Meiosis in an autotriploid pearl millet. Caryologia 21:11-15.

Pantulu JV and Venkateswarlu J (1968) Morphology of the pachytene chromosomes of Pennisetum purpureum Schum. Genetica 39:41-44.

Pantulu JV and Rao K (1982) Cytogenetics of pearl millet. Theor Appl Genet 61:1-17.

Peschke VM and Phillips RL (1992) Genetic implications of somaclonal variation in plants. Adv Genet 30:41-75.

Pickersgill B (1991) Cytogenetics and evolution of Capsicum L. In: Gupta PK and Tsuchiya T (eds) Chromosome Engineering Plants: Genetics, Breeding, Evolution Part A. Elsevier, New York, pp 139-160.

Pijnacker LP, Ferwerda MA, Puite KJ and Schaart JG (1989) Chromosome elimination and mutation in tetraploid somatic hybrids of Solanum tuberosum and Solanum phureja. Plant Cell Report 8:82-85.

Powell JB and Burton GW (1969) Chromosome interchanges of spontaneous origin in pearl millet Pennisetum typhoides. Crop Sci 9:252-253.

Raman VS (1964) Progress of cytogenetic research in Madras State. In: Krishnamurthi S (ed) Advances in Agricultural Sciences and Their Applications. The Madras Agric Jour, Coimbatore, India, pp 122-143.

Rao NS (1929) On the chromosome numbers of some cultivated plants of south India. Indian J Bot Sci 8:126-128.

Riley R and Chapman V (1958) Genetic control of the cytologically diploid behaviour of hexaploid wheat. Nature 182:713-715. 
Sharma AR and Sharma A (1994) Chromosome Techniques. Harwood Academic Publishers, Switzerland, 368 pp.

Sears ER (1976) Genetic control of chromosome pairing in wheat. Ann Rev Genet 10:31-51.

Sethi GS, Kalia HR and Ghai BS (1970) Cytogenetical studies of three interspecific hybrids between Pennisetum typhoides Stapf and Hubb. and P. purpureum Schumach. Cytologia 35:96-101.

Sree Rangasamy SR (1972) Cytological studies on diploid and polyploid taxa of the genus Pennisetum Rich. Genetica 43:257-273.

Sujatha DM, Manga V, Subba Rao MV and Murty JSR (1989) Meiotic studies in some species of Pennisetum (L.) Rich. (Poaceae). Cytologia 54:641-652.
Sybenga J (1992) Cytogenetics in Plant Breeding. SpringerVerlag, Berlin, 469 pp.

Techio VH, Davide LC and Pereira AV (2005) Genomic analysis in Pennisetum purpureum $\times$ P. glaucum hybrids. Caryologia 58:28-33.

Veyret Y (1957) Les chromosomes somatiques chez quelques spèces de Pennisetum (Somatic chromosomes in some species of Pennisetum). Agronomia Tropical 12:595-598.

Vieira MRAMCM (1992) Interacção genómica em alopoliplóides da tribo Triticeae. Coimbra, http://www.uc.pt/Teses/Gbio. vieira.html. 